\title{
Enliven Photographs: Enriching User Experience
}

\author{
Akshay Darbari ${ }^{1}$ and Pragya Agrawal ${ }^{2}$ \\ 1 Tata Elxsi Ltd., Bangalore, India \\ 2 Infosys Technologies Ltd., Bangalore, India
}

\begin{abstract}
This paper is based on the study aimed at giving a new direction to Photographs, keeping in mind the growing needs of the people and enriching day-to-day experience vis-à-vis paper based photograph. A survey was conducted which revealed few startling but interesting facts as to what more the end-user wants than a mere 'physical paper-based photograph'. This paper talks about the survey, response by the participants, results derived from them, current work and future direction.
\end{abstract}

\section{Introduction}

“Ah! Nostalgia..." exclaimed Maya, holding a photograph of her daughter when she was a kid. Maya is trying hard to recollect the moment when her daughter spoke her first words or when her daughter took her first steps and enacted à la Neil Armstrong's giant leap in her own way.

"Pictures that tell their own story maybe worth more than a thousand words". How many of us remember the background of a photograph, long after it's been shot? It's an interesting paradox that with time, people no longer remember the event or context well enough to recollect or relive that moment.

This paper is based on the study aimed at

- Providing a new direction to Photograph, keeping in mind the growing needs of the people and how to meet those,

- Enriching day-to-day experience of people,

- Providing intelligent solutions for improving the quality of life and

- Findings way of expanding boundaries of our personal space and create a world of seamless connectivity.

A survey [2] was conducted where participation of the end-user was encouraged. This survey revealed few startling but interesting facts as to what more the end-user wants than a mere 'Physical Paper Photograph'. The challenge lies in providing solutions to fulfill the end-user's requirements. If this happens, the world of photographs will see a revolution and the way in which we look and handle paper-

Ilease twe the following forma when siting this chapter:

Darbari, A., Agrawal, P., 2007, in IFIP International Federation for Information Processing, Volume 24I, Home Informatics and Telematics: ICT for the Next Billion, eds. Venkatesh, A., Gonsalves, T., Monk, A., Buckner, K., (Bostor: Springer), pp. 215-219. 
based photographs as of now will also change. The photographs won't be the same again.

\section{The Study}

The survey was conducted on randomly chosen user base of 100 , with people from different age group, gender, and location. Each participant was asked a carefully defined set of seven questions. The participants were asked to answer the following questions online as part of the survey:

1. What is the significance of photographs to you?

2. Do you prefer viewing photographs as a paper based activity or watching it on screen?

3. What do you think of sharing photographs on screen rather than on paper?

4. Do you feel something is missing in the photographs? What is it?

5. What other media do you like to augment with photographs? Text/handwriting/audio/short video/others

6. How do you think this media will enhance the status quo of photographs?

7. Would you like photographs to be interactive? What is your idea of interacting with the photograph?

\section{The Response}

The response received from the participants, is compiled as follows:

\section{- What is the significance of photographs to you?}

Photographs in general are a treasure trove of memoirs for all and encompass mood, emotions, and feelings that influence reflexes, perception, cognition and behavior. Majority of the participants replied that they view photographs to recollect past events and refresh their memories followed by Fun/recreation, Hobby, Miscellaneous respectively as shown in figure 1 .

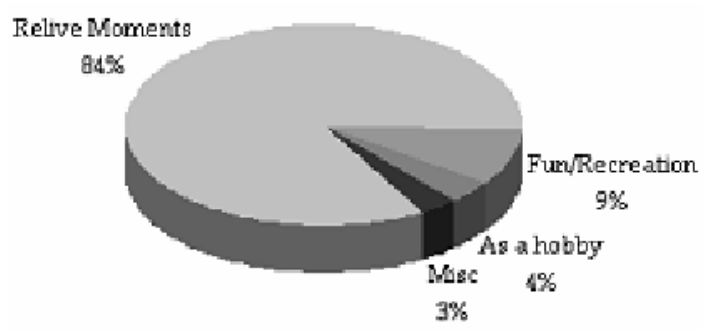

Fig. 1. Significance of photographs to people in percentage 


\section{- Do you prefer viewing photographs as a paper based activity or watching it on screen?}

In this digital age, even the viewing experience has changed from paper based to digital photographs on screen. The users attribute this change to the ease of editing and sharing of photographs, which is not possible in case of paper-based photograph. But the survey shows that even though users are inclined towards digital photographs, people still enjoy viewing photographs as a paper-based activity rather than on screen. Users associate this with the nostalgia attached with the paper based photographs.

\section{- What do you think of sharing photographs on screen rather than on paper?}

As mentioned in the above section people find it more convenient to share the photographs on screen than on paper. Digital photographs can be shared on screen or Internet and can be edited easily without any hassle. Creation of multiple copies of the same photograph is also simple, less time consuming and without any investment.

\section{- Do you feel something is missing in the photographs? What is it?}

Though the question sounded a bit out of place to the participants, but when explained most of them felt that the answer is 'yes'. The participants feel that with time the context attached with the photographs is lost and it is difficult to recollect and relive that moment.

- What other media do you like to augment with photographs? Text/handwriting/audio/short video/others

This was another complex question for the participants. Maximum people opted for audio as a media, which will help in annotating the photographs and enhance the value of the photograph the most, followed by video, text and others respectively.

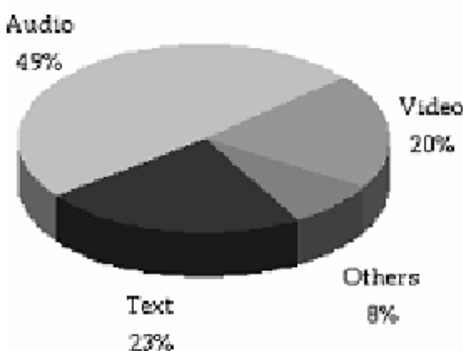

Fig. 2. People choice of Media Augmentation with Photograph

\section{- How do you think this media will enhance the status quo of photographs?}

These media are going to indirectly increase the value of the photograph. The viewing experience will enrich the user's viewing experience and help them to relive the moment. 
Another interesting finding from the survey is that, the effect of different media is different for different people. Therefore, different people prefer different media to help invoke emotions.

- Would you like photographs to be interactive? What is your idea of interacting with the photograph?

The participants were extremely creative and gave interesting answers to this question. A few of the responses are replicated in this paper to give a feel of what the participants want:

- "Interactive...Yes... if it means that suppose I want to know more about the background and surroundings of a particular location being shot..."

- "Why not? Image maps as in HTML, links to other image libraries...eg clicking on A's pic (in, say a family photo) takes one to an album containing A's pics..."

- "ya that will definitely be useful to handle bad or dated or damaged copied or to selectively view photos, through voice."

- "...I couldn't comprehend how could a photograph be interactive... If the only implication derives from the fact that the same picture can be viewed from multiple angles..."

And the replies on the lighter side:

- "You should invent something like star trek such that when I see a photograph Mr. Spock just presses a button and I can be with the person...."

- "Kissing it goodnight and tucking it under the pillow..."

\section{Results}

Results After the survey a wish list was prepared. The wish list was based on the survey responses and what normally people would expect if the solution were based on a digital photograph.

The wish list is summarized as under:

- Preference for paper based photograph than digital

- Augmenting other media for enriching viewing experience and help relive the moment

- Annotations using any media

- Better photograph management

- Restoring photograph in case of wear out

- Search, browse, index and retrieve

- Communication between photographs

This wish list was shared with the participants and was asked their opinion. The participants found it hard to visualize how the wish list can be realized. 


\section{Future Directions}

Perhaps, if the wish list is to be implemented for digital photographs the problem might not be that complex. The challenge lies in offering solutions for the survey outcome of user preference for paper based physical photographs.

The participants feel that if not fictitious, this is quite a futuristic solution and question its viability. The authors disagree and are of the opinion that the time has come to provide such user-friendly solutions to enrich common day-to-day experiences.

The authors are currently working towards providing solution for the paper-based photograph. So far, they have been successful in generating enough interest in the idea from all quarters and intend to bring a revolution in the world of paper-based photographs.

\section{Acknowledgement}

We express our deep sense of gratitude to those who participated in the 'Enliven Photographs' survey and replied back whenever we wanted their feedback. We would also like to thank our Parents, who always stood by us whenever we were in need of them. We regret any inadvertent omissions.

\section{References and Citations}

1. Enliven Photograph; http:/home.graffiti.net/akshay.darbari:graffiti.net/html/ep.html

2. Enliven Photograph Survey 